\title{
Uterine didelphys: a rare case report
}

\section{Lopamudra Jena*, Jyoti Narayan Puhan, Sujata Swain, Shyama Kanungo}

Department of Obstetrics \& Gynaecology, S C B Medical College, Cuttack, Odisha, India

Received: 25 July 2015

Revised: 23 August 2015

Accepted: 29 August 2015

\author{
*Correspondence: \\ Dr. Lopamudra Jena, \\ E-mail: julijena82@gmail.com
}

Copyright: (c) the author(s), publisher and licensee Medip Academy. This is an open-access article distributed under the terms of the Creative Commons Attribution Non-Commercial License, which permits unrestricted non-commercial use, distribution, and reproduction in any medium, provided the original work is properly cited.

\begin{abstract}
Uterus Didelphys is a rare congenital abnormality of uterus in which uterus is present as a paired organ when the embryogenetic fusion of the mullerian ducts fail to occur. As a result there occurs a double uterus with two separate cervices and often a double vagina as well. Each uterus has a single horn linked to the ipsilateral fallopian tube that faces its ovaries. We present a case of a multiparous lady who has uterus didelphys has previous two normal vaginal deliveries and during her third delivery she has prolapse of non-gravid uterus during second trimester which reduced gradually but spontaneously with advancing gestational age and she delivered a male child by caesarean section due to oligohydramnios with breech presentation during current pregnancy.
\end{abstract}

Keywords: Uterus Didelphys, Mullerian Ducts, Prolapse

\section{INTRODUCTION}

The uterus is formed during embryogenesis by the fusion of the two paramesonephric ducts (mullerian ducts). The two mullerian ducts normally fuse to form the single uterine body. A didelphic uterus will have a double cervix and a double vagina. The cause of the fusion failure is not known. Associated defects may affect the vagina, the renal system and less commonly the skeleton. The condition is less common than the other uterine malformations: arcuate uterus, septate uterus and bicornuate uterus. It has been estimated to occur in $1 / 3000$ women. ${ }^{1}$

\section{CASE REPORT}

A 25 years gravid 3 para 2 was admitted through our OPD at 33 weeks 2 days of gestation with complains of something coming out of vagina for 2 days. On examination there was a longitudinal vaginal septum along with prolapse of the non-gravid uterus and cervix which was not congested or hypertrophiedin one side of septum and another cervix was visualised well in its anatomical position in the other side of septum. She was admitted to our antenatal ward. The prolapsed gradually reduced with dressing and also with increasing gestational age [Figure 1]. During that period all routine blood parameters were within normal limits and ultrasound showed normal fatal biophysical profile for her gestational age. She was discharged with advice of regular antenatal follow up. She came to OPD at a gestational age of 38 weeks 4 days for follow up. On abdominal examination foetus was in breech presentation. On per vaginal examination cervix was short, soft, os was closed, presenting part was high up. A USG was done for FBPP which showed a single intra uterine pregnancy of average gestational age of 37 weeks 1 day with approximate weight of $2.7 \mathrm{~kg}$ with breech presentation with oligohydramnios with posterior fundic placenta. So with this she was planned for elective caesarean section. LSCS under spinal anaesthesia was performed, a male child of $2.8 \mathrm{~kg}$ was delivered by breech extraction, placenta and membranes were delivered into liquor was clear but reduced. On examination there was another uterus right to the gravid uterus with which the right fallopian tube was attached 
and right ovary was also attached with ovarian ligament, the left tube and left ovary was attached to the gravid uterus which was on left side [Figure 2 and 3]. Then uterus was closed in double layers and abdomen was closed in layers after maintaining proper haemostasis .Bilateral tubal ligation was done on patients request. Postoperative period was uneventful and she was discharged on $7^{\text {th }}$ postoperative day with advice of follow up.

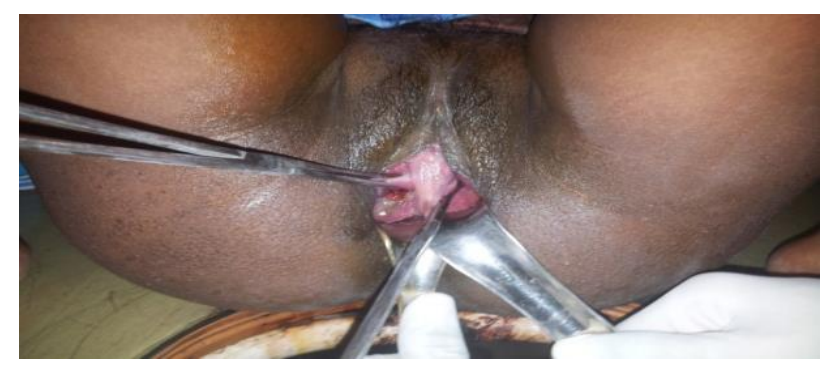

Figure 1: Double vagina and right side cervix.

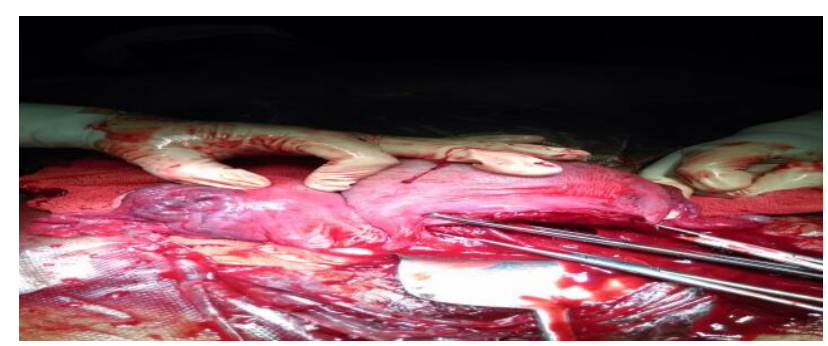

Figure 2: Double uterus with right sided nongravid uterus with right side tube and ovary, left sided gravid uterus left side tube and lower segment caesarean incision.

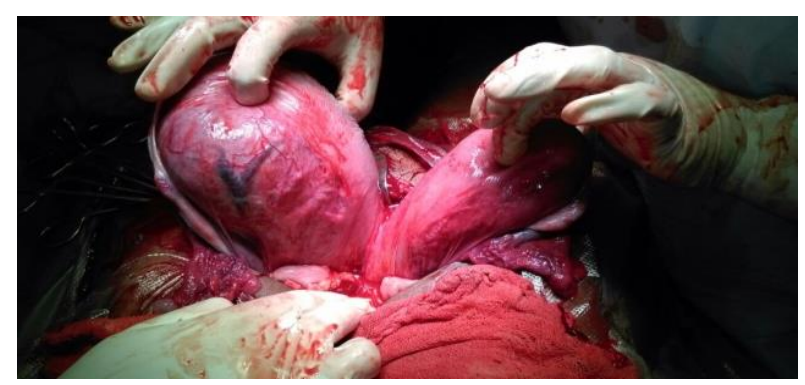

Figure 3: Double uterus with right sided nongravid uterus with right side tube and ovary, left sided gravid uterus left side tube and lower segment caesarean incision.

\section{DISCUSSION}

Mullerian duct anomalies affect between $0.1 \%$ and $3 \%$ women. In the most extreme form of the mullerian duct non-fusion, uterus didelphys results, with complete duplication of the uterus, cervix and vagina. This anomaly accounts for $11 \%$ of uterine malformations and is typically asymptomatic. ${ }^{2-4}$ Patients with a double uterus may need special attention during pregnancy as premature birth and malpresentation are common. Caesarean section was performed in $82 \%$ of patients reported by Heinonen. ${ }^{5}$ Uterus didelphys in certain studies has also been found to be associated with higher rate of infertility, spontaneous abortion, intrauterine growth retardation and post-partum bleeding. ${ }^{6}$

\section{CONCLUSION}

Mullerian duct anomalies are rare and usually associated with various clinical manifestations which range from dysmenorrhoea at puberty to preterm delivery and increased rate of caesarean section during reproductive age group. So through investigations should be done in cases of spasmodic dysmenorrhoea and case of second trimester recurrent abortions to exclude uterine anomalies which includes ultrasound, MRI and hysteroscopy.

\section{REFERENCES}

1. Grimbizis GF, Camus M, Tarlatzis BC, Bontis JN, Devroey P. "Clinical implications of uterine malformations and hysteroscopic treatment results". Human Reproduction Update. 2001;7(2):161-74.

2. Carrington BM, Hricak $H$, Nuruddin $\mathrm{RN}$, et al. Mullerian ducts anomalies: MR imaging evaluation. Radiology. 1990;176:715-20.

3. Cansole D, Tamburrini S, Barresi D, et al. The value of MR imaging in the evaluation of Mullerian ducts anomalies. Radiol Med. 2001;102:226-32.

4. Brown MA. MR imaging of benign uterine disease. Magn Reson Imaging Clin N Am. 2006;14:439-53.

5. Heinonen PK. "uterus diadelphys: a report of 26 cases" European journal of obstetrics \& gynecology $\&$ reproductive biology. 1984;17(5):345-50.

6. Pui M. "Imaging diagnosis of congenital uterine malformation" Computerized medical imaging and graphics. 2004;28(7):425-33.

Cite this article as: Jena L, Puhan JN, Swain S, Kanungo S. Uterine didelphys: a rare case report. Int J Reprod Contracept Obstet Gynecol 2015;4:1613-4. 